\title{
Is there a relation between sleeping habits and nocturnal bruxism, temporomandibular disorders, dental trauma and caries among children?
}

\author{
Asli Topaloglu Ak${ }^{1}$, Huseyin Kurtulmus², sila basa ${ }^{2}$, Sevgi Zorlu ${ }^{2}$, Ozge Can Kolcu ${ }^{2}$, and \\ Osman Sabuncuoglu ${ }^{3}$ \\ ${ }^{1}$ Istanbul Aydin Universitesi \\ ${ }^{2}$ Affiliation not available \\ ${ }^{3}$ Marmara University School of Medicine
}

February 5, 2021

\begin{abstract}
Objective: Sleep disorders are common among children and have a negative impact on growth and development. Recently reports demonstrate a possible association with oral findings as well. The aim of this study was to evaluate the possible association between sleeping habits, bruxism, temporomandibular disorders (TMD), traumatic dental injuries (TDI) and dental caries in children. Material and Methods: A cross-sectional study was carried out at IAU Faculty of Dentistry with a representative sample of a hundred children aged between 6-13. Children's Sleep Habits Questionnaire (CSHQ) was completed by their parents. Intra oral examination was carried out in a clinical setting and presence of nocturnal bruxism, history of TDI were recorded for each child. Results: Among sleeping habits, bed time resistance was found significantly related with children who had nocturnal bruxism and temporomandibular disorders. Untreated dental caries was also found significantly associated with sleep fragmentation. However, no relation was found with traumatic dental injuries. Conclusion: Children with symptoms of bruxism, TMD and untreated dental caries might experience negative impacts on their sleeping habits and characteristics. Pediatricians and pedodontists should work in collaboration to identify causes and clinical features of sleeping habits and disorders in order to avoid negative effects on stomatognathic system.
\end{abstract}

Is there a relation between sleeping habits and nocturnal bruxism, temporomandibular disorders, dental trauma and caries among children?

\section{ABSTRACT}

Aim: Sleep disorders are common among children and have a negative impact on growth and development. Recently reports demonstrate a possible association with oral findings as well. The aim of this study was to evaluate the possible association between sleeping habits, bruxism, temporomandibular disorders (TMD), traumatic dental injuries (TDI) and dental caries in children.

Methods: A cross-sectional study was carried out at IAU Faculty of Dentistry with a representative sample of a hundred children aged between 6-13. Children's Sleep Habits Questionnaire (CSHQ) was completed by their parents. Intra oral examination was carried out in a clinical setting and presence of nocturnal bruxism, history of TDI were recorded for each child.

Results: Among sleeping habits, bed time resistance was found significantly related with children who had nocturnal bruxism and temporomandibular disorders. Untreated dental caries was also found significantly associated with sleep fragmentation. However, no relation was found with traumatic dental injuries. 
Conclusion: Children with symptoms of bruxism, TMD and untreated dental caries might experience negative impacts on their sleeping habits and characteristics. Pediatricians and pedodontists should work in collaboration to identify causes and clinical features of sleeping habits and disorders in order to avoid negative effects on stomatognathic system.

Keywords: Sleeping habits, Sleep disorders, Children's Sleep Habits Questionnaire (CSHQ), bruxism, temporomandibular disorders, malocclusion, traumatic dental injuries, dental caries, children

\section{What is already known about this topic?}

Sleeping problems of have been associated with bruxism and temporomandibular disorders in adult population. Dental caries presence was found to be related to sleep fragmentation leading to inadequate sleep in children.

\section{What does this article add?}

The present study confirms the sleeping habits are associated with sleep bruxism and symptoms of temporomandibular disorders in children as well. Bed time resistance is found to be related to nocturnal bruxism and TMD symptoms. Furthermore, sleep fragmentation is found to be associated with untreated dental caries due to severe pain mostly rising from seconder acute pulpitis cases. Pediatric dentists should be aware of the fact that oral finding, symptoms can affect the quality of sleep. Likewise, pediatricians must integrate with pediatric dentists to diagnose, treat and avoid sleep related oral health problems.

Is there a relation between sleeping habits and nocturnal bruxism, temporomandibular disorders, dental trauma and caries among children?

\section{INTRODUCTION}

It is well noted that sleep has an important effect on the growth and development of a child. Yet, sleep disorders are common in children from infancy through adolescence. ${ }^{(1-3)}$ Sleeping habits and patterns should be detected by parents, and pediatricians prudently to avoid possible adverse effects on general health. ${ }^{(4)}$ Sleeping habits may vary from resistance to bedtime, delayed and fragmented sleep to inability to sleep alone. These are all associated with the socio-cultural, physical, emotional and neurological development. ${ }^{(5,6)}$

In order to identify sleeping habits of a child many techniques and instruments and questionnaires are available. The Children's Sleep Habits Questionnaire (CSHQ) is a parent-proxy valid and reliable instrument that investigates children's sleep habits and sleep-related difficulties. ${ }^{(7)}$

Sleeping disorders are defined mainly as the dyssomnia and parasomnia according to the International Classification of Sleep Disorders (ICSD). ${ }^{(8)}$ Dyssomnia defines inadequate, excessive or poor quality of sleep whereas parasomnia indicates behavioral problems that occur in sleep such as sleep apnea, sleep terror, sleepwalking, enuresis and bruxism. (3)

Exacerbated nocturnal bruxism may lead to an imbalance in the stomatognathic system. This may cause heterogeneous musculoskeletal disorders, including temporomandibular joint and/or related structures in the long term. The perception of discomfort leads to the prevention of stability in the stomatognathic system with the presence of dysfunction. ${ }^{(9-11)}$ This chronic disorder and fatigue is a condition that affects quality of life and sleep negatively. Hence early diagnosis and follow ups are crucial. Notably, child bruxers are reported to have fragmented sleep which affects the sleep quality adversely. ${ }^{(12-14)}$ One other factor that can affect sleeping pattern is dental caries which can also lead to awakening from sleep at nights. A cohort study revealed that late bed time was associated with dental caries incidence as well. ${ }^{(15)}$ Like chain reaction, poor sleep quality impacts the attention level and motor skills. This might increase the frequency of dental trauma incidence. ${ }^{(16,17)}$ Considering sleep problems are common in the pediatric population, its potential relation with bruxism, tmd, tdi and dental caries are in scope of researchers' interest. Therefore, the aim of this study was evaluate the possible association between sleeping habits, bruxism, temporomandibular disorders (TMD), traumatic dental injuries (TDI) and dental caries through CSHQ in children aged between 6-13 years. 


\section{METHODS}

The study protocol was approved by the Human Research Ethics Committee of the Istanbul Aydın University (2020/169). The study was carried out in full compliance with the World Medical Association Declaration of Helsinki.

This cross-sectional study involved 100 children aged between 6-13 years old who referred to Istanbul Aydin University Faculty of Dentistry Department of Pediatric Dentistry with their parents for their routine controls or dental treatment. The exclusion criteria included systemic diseases, fixed/removable intra/extra oral appliance and lack of cooperation. Written consent was obtained.

The data on sleeping habits were collected through parent proxy report through Children's Sleep Habit Questionnaire (CSHQ) that has 33 questions. It is segmented in four main subjects: bedtime resistance, sleep behavior problems, sleep fragmentation and daytime sleepiness. Each item has three response options regarding how often the investigated conditions occurred the previous week. Frequencies were coded as 'usually' if the specified behavior occured more than four times a week, 'sometimes' for 2-4 times a week and 'rarely' for 0-1 time a week. Presence of bruxism and history of traumatic dental injury was recorded as well.

Intra oral examinations were done by one operator in order to avoid inter-operator bias in a clinical setting. Carious lesions were recorded using WHO criteria. The clinical examination included TMJ examination, Angle Classification and malocclusion. Canines and incisor teeth and adjacent soft tissues were examined for clinical findings of traumatic dental injuries.

TMJ examination was rated according to Helkimo anamnestic and clinical pain-dysfunction index. Lack of symptoms were encoded as 'Grade 0', mild symptoms (feeling of fatigue in the muscles, muscle stiffness and / or pain, masticating muscular disorders) were encoded as 'Grade 1'and serious symptoms (not being able to open the mouth too much, jaw locking or dislocation, pain and limitation in mandibular movements, pain in the area of the tmj and / or masticatory muscles, condyle-disc irregularities in tmj) were encoded as 'Grade 2'.

Occlusion was recorded according to Angle Classification and presence of overjet, anterior open bite, overbite, crowding, spacing, crossbite was also noted as malocclusion.

\section{Statistical Analysis}

The statistical analysis was conducted using SPSS 25 (IBM Corp. Released 2017. IBM SPSS Statistics for Windows, Version 25.0. Armonk, NY: IBM Corp.) Data were analyzed by Fisher's Exact Test and Chi Square test. In cases where the expected frequencies are less than $20 \%$, evaluation was made with the "Monte Carlo Simulation Method" to include these frequencies in the analysis. For the significance level of the tests, $\mathrm{p}<0.05$ and $\mathrm{p}<0.01$ value were accepted.

\section{RESULTS}

A total of 100 patients (55 female and 45 male) who met the inclusion criteria and their parents were included in this study. Most of these parents were represented by mothers $(76 \%)$, followed by fathers $(21 \%)$ and other relatives $(3 \%)$.

$40 \%$ of parents reported that their children had nocturnal bruxism. Gender was found insignificant with the presence of bruxism. The prevalence of TMJ disorder symptoms was $9 \%$. A significant relation was found among children with nocturnal bruxism and TMD symptoms. The presence of bruxism was significantly higher in individuals who had TMJ disorder symptoms $(\mathrm{p}<0,05)$. (Table-1)

There was a statistically significant relation between bruxism and bedtime resistance. The presence of bruxism was significantly higher in child who had bedtime difficulties $(\mathrm{p}=0.02)$ (Table-2)

A statistically significant relation between children with TMJ disorder symptoms and bed time resistance $(\mathrm{p}=0.02)$ and sleep behavior disorder was noted. $(\mathrm{p}=0.04)$ (Table-3) 
The prevalance of untreated dental caries was $98 \%$. The presence of caries was also found significantly associated with awakening from sleep at nights and sleep fragmentation. $(\mathrm{p}=0.001)$ (Table- 4$)$

The permanent molar relationship was \%79 Class I, \%11 Class II and \%10 Class III according to Angle Classification. There was no significant relation found between the sleeping characteristics.

The prevalence of traumatic dental injury was $22 \%$. However, no significant relation was found between sleeping habits. $(\mathrm{p}>0.05)$

\section{DISCUSSION}

Today, sleeping habits of children are in the focus of not only pediatricians but dentists as well. The relationships between sleeping habits and possible TMJ problems, malocclusion, TDI, bruxism and dental caries have been investigated recently and still holds a major area of research interest. ${ }^{(15-17)}$

In this study, Turkish Version of CSHQ was used for data colletion. This questionnaire was translated to Turkish and validated and reported to be a reliable instrument for assessing sleep habits and screening possible sleep problems of Turkish children. ${ }^{(18)}$ Although there are various concerns that parent's notifications may differ from the child's self-report, scales based on parents' reports are frequently used in both psychiatry and pediatric practices. ${ }^{(19)}$ It is noteworthy that, American Academy of Sleep Medicine considers the reports of parents to be reliable and sufficiently objective for use in epidemiological studies. ${ }^{\left({ }^{8}\right)}$

In the present study, prevalence of sleep bruxism was found $40 \%$. However bruxism prevalance among children displays a fluctuating pattern. ${ }^{(4,9,11,20)}$ In a systematic review by Machado et al., the prevalence rates of sleep bruxism vary from $5.9 \%$ to $49.6 \%$, and these variations show can be attributed to different diagnostic criteria used for bruxism. ${ }^{(9)}$ Therefore, evidence-based studies with standardized and validated diagnostic criteria are required for accurate assessments. ${ }^{(9)}$ Insana et al. reported that sleep bruxism affected more boys than girls. ${ }^{(20)}$ In the study by Cheifetz et al., there was also a trend for males to be more likely to brux than females. ${ }^{(11)}$ However, in the present study no significant relation was found between presence of sleep bruxism and gender.

Potential sleep bruxism is hereditary. Muscle pains, snoring and mouth breathing are important signals for detecting sleep bruxism in children. Sleep fragmentation was also found associated with sleep bruxism. ${ }^{(29)}$ Nocturnal agitation and nightmares were found to be associated with possible nocturnal bruxism. Moreover, young children with evening chronotype were reported to have an tendency toward possible sleep bruxism. ${ }^{(30)}$

In the present study, nocturnal bruxism was found to be associated with sleeping habits. The presence of bruxism was significantly higher in child who had bedtime difficulties. In parallel to this finding, Oner et al. reported that sleep quality was associated with nocturnal bruxism in children. ${ }^{(21)}$

$9 \%$ of the children showed TMJ disorder symptoms in the present study. TMD prevalence in children and adolescents vary from 16 to $68 \% .{ }^{(22)}$ Mostly, study populations' subjective TMD symptoms were jaw clicking , muscle tenderness, pain on opening and limited opening. ${ }^{(11)}$

In the present study, there was a statistically significant relationship between TMJ disorders symptoms with sleeping characteristics and and bruxism. Children with bed time resistance were more likely to have TMD disorder symptoms. In contrast to our findings, Cheifetz et al., reported that TMD symptoms were not associated with bruxism. ${ }^{(11)}$ However, our findings were in line with Lei et al. that reported TMD symptoms were significantly associated with psychological distress and disturbed sleep. ${ }^{(23)}$

When functional changes that occur with factors such as occlusal conflicts reach a certain level, they begin to produce textural changes. In the present study, the prevalence of malocclusion was found $62 \%$ among children, and Class I was the most frequent molar relationship (79\%). Numerous studies have been published on the prevalence of malocclusion with reported prevalence ranging from $39 \%$ to $98 \% .^{(24,25)}$ Our result is in line with Sayin et al., reporting that Class I was the most frequently seen malocclusion in Turkish orthodontic population. ${ }^{(26)}$ However, no significant relation was found between malocclusion and sleeping habits which may be attributed to limited sample size. 
Factors such as traumas and parafunctional habits can change the existing structural tolerance of TMJ. In this study, the prevalence of traumatic dental injury was $22 \%$. In a study by Carvalho et al., the overall prevalence of dental trauma was found \%37.1 in school-children. ${ }^{(27)}$ No significant correlation was found between sleep disorders and traumatic dental injuries in our study. Based on previous literature, traumatic dental injuries tended to be associated with sleep disorders. Sleep disorders in children can affect motor skills, cognition and concentration. A bad night sleep can affect a person's mood and concentration the next day. ${ }^{(17)}$ It was stated that sleep deprivation was associated with accidental injuries; $86 \%$ increase in trauma incidences when children slept less than 10 hours the night before the accident. ${ }^{(28)}$ In addition, waking up three to four times at night, which is an indication of agitated sleep, was associated with a higher traumatic dental injury prevalence.

Daytime sleepiness is the main aspect of sleep behavior associated with the prevalence of traumatic dental injuries and dental caries. ${ }^{(17,31)}$ The prevalance of dental caries is very high in the present study which unfortunately reflects the unmet oral health care in Turkey ${ }^{(32)}$ Subsequently, retardation in growth, missing of school and fragmentation of sleep is inevitable. ${ }^{(33)}$ Dental caries was found associated with sleep fragmentation in the present study which is also in line with previous reports. ${ }^{(31,33)}$

It should be noted that various limitations should be considered when interpreting the data in this study. Sleep disorders and bruxism was evaluated based on the subjective judgment of parents. The role of the family is very important in the diagnosis of pediatric nocturnal bruxism cause it occurs by recognizing the characteristic sounds produced by the grinding of teeth at night. ${ }^{(4)}$ Therefore, although parents' answers are subjective in this study, it is the most appropriate method to collect data for reliable and large sample studies.

The relationship between sleep problems and higher bruxism and temporomandibular disorders prevalence suggests that sleep samples should be investigated in scientific research using other methodological diagnostic methods to confirm these findings. In this manner, data on sleep behaviors obtained when collecting the patient's history before a dental appointment can be useful for a better orientation to parents in preventing bruxism and temporomandibular disorders. Consequently, integration with paediatricians, pedodontists and psychiatrics is the key factor to diagnose, treat and avoid sleep related oral health problems.

\section{CONCLUSION}

In this study, sleeping habits were significantly associated with bruxism, temporomandibular disorders and dental caries in children aged between 6-13. No significant correlation was found, however, between sleep characteristics and malocclusion and traumatic dental injuries. Pediatricians and pediatric dentists should work in partnership to identify causes and clinical features of sleeping disorders in order to prevent possible oral and dental damages in children.

\section{ACKNOWLEGMENTS}

Authors would like to thank Istanbul Aydin University Dental Faculty staff for their support and special thanks to Assoc. Prof Mustafa Agah Tekindal for his assistance in statistical analysis.

\section{REFERENCES}

1. Rana M, Riffo Allende C, Mesa Latorre T, Rosso Astorga K, Torres AR. Medicina (B Aires). Sleep in children: physiology and update of a literature review. Medicina (B Aires) 2019; 79 Suppl 3: 25-28.

2. Anders TF, Eiben LA. Pediatric sleep disorders: a review of the past 10 years. J Am Acad Child Adolesc Psychiatry 1997; 36:9-20.

3. Johnson KP. Pediatric sleep disorders. K Cheng,KM Myers (Eds.), Child and Adolescent Psychiatry The Essentials, Philadelphia, Lippincott Williams and Wilkins, 2005.

4. Tavares Silva C, Calabrio IR, Serra-Negra JM, Fonseca-Gonçalves A, Maia LC. Knowledge of parents/guardians about nocturnal bruxism in children and adolescents. Cranio 2017; 35(4): 223-227.

5. Durduran Y, Pekcan S, Çolpan B.Niger Sleep habits and related factors in kindergarten children. J Clin Pract. 2019 Sep;22(9):1218-1223. 
6. Carneiro IM, Fonseca P, Ferreira R. Children's Sleep Habits Questionnaire in Two Subpopulations from Cape Verde and Mozambique: Exploratory and Regression Analysis. Acta Med Port. 2019 Oct 1;32(10):628-634.

7. Owens JA, Spirito A, McGuinn M. The Children's Sleep Habits Questionnaire (CSHQ): psychometric properties of a survey instrument for schoolaged children. Sleep 2000; 15:1043-1051.

8. American Sleep Disorders Association. International Classification of Sleep Disorders, Revised: Diagnostic and Coding Manual. Rochester, MN, American Sleep Disorders Association, 1997.

9. Machado E, Dal-Fabbro C, Cunali PA, Kaizer OB. Prevalence of sleep bruxism in children: a systematic review. Dental Press J Orthod. 2014; 19(6): 54-61.

10. Herrera M, Valencia I, Grant M, Metroka D, Chialastri A, Kothare SV. Bruxism in children: effect on sleep architecture and daytime cognitive performance and behavior. Sleep. 2006; 29: 1143-1148.

11. Cheifetz AT, Osganian SK, Alfred EM, Needleman HL. Prevalence of bruxism and associated correlates in children as reported by parents. J Dent Child. 2005; 72: 67-73.

12. Bertoli FMP, Bruzamolin CD, Pizzatto E, Losso EM, Brancher JA, de Souza JF. Prevalence of diagnosed temporomandibular disorders: A cross-sectional study in Brazilian adolescents. PLoS One. 2018; 13(2): e0192254.

13. Lei J, Fu J, Yap AU, Fu KY. Temporomandibular disorders symptoms in Asian adolescents and their association with sleep quality and psychological distress. Cranio. 2016; 34(4): 242-249.

14. Egermark I, Carlsson GE, Magnusson T. A 20-year longitudinal study of subjective symptoms of temporomandibular disorders from childhood to adulthood. Acta Odontol Scand. 2001; 59(1): 40-48.

15. Alqaderi H, Tavares M, Al-Mulla F, Al-Ozairi E, Goodson JM. Late bedtime and dental caries incidence in Kuwaiti children: A longitudinal multilevel analysis.Community Dent Oral Epidemiol. 2020 Jun;48(3):181-187.

16. Sabuncuoglu O. Understanding the relationships between breastfeeding, malocclusion, ADHD, sleepdisordered breathing and traumatic dental injuries. Medical Hypotheses 2013; 80: 315-320.

17. Todero SRB, Cavalcante-Leao BL, Fraiz FC, Rebellato NBL, Ferreira FM. The association of childhood sleep problems with the prevalence of traumatic dental injury in schoolchildren. Dent Traumatol 2019; 35(1): 41-47.

18. Perdahlı Fis N, Arman A, Ay P, Topuzoglu A, Güler AS, Gokce Imren S, Ersu R, Berkem M. Çocuk Uyku Alışkanlıkları Anketinin Türkçe Geçerliliği ve Güvenilirliği. Anadolu Psikiyatri Dergisi 2010; 11: 151-160.

19. Varni JW, Limbers CA, Burwinkle TM. Parent proxy-report of their children's health-related quality of life: an analysis of 13,878 parents' reliability and validity across age subgroups using the PedsQL 4.0 Generic Core Scales. Health Qual Life Outcomes 2007; 5:2-11.

20. Insana SP, Gozal D, McNeil DW, Montgomery-Downs HE. Community based study of sleep bruxism during early childhood. Sleep Med. 2013; 14(2): 183-188.

21. Öner P, Barut Y, Öner Ö, Üneri ÖŞ, Bodur Ş, Turgut S, Munir KM. Çocuklarda Uyku Ölçeği'nin Geçerlik ve Güvenirliği. Klinik Psikofarmakol Bulteni 2009; 19(4): 382-395.

22. Sena MF, Mesquita KS, Santos FR, Silva FW, Serrano KV. Prevalence of temporomandibular dysfunction in children and adolescents. Rev Paul Pediatr. 2013; 31(4): 538-545.

23. Lei J, Fu J, Yap AU, Fu KY. Temporomandibular disorders symptoms in Asian adolescents and their association with sleep quality and psychological distress. Cranio 2016: 34(4):242-249.

24. Todor BI, Scrobota I, Todor L, Lucan AI, Vaida LL. Environmental factors associated with malocclusion in children population from Mining Areas, Western Romania. Int J Environ Res Public Health. 2019;16(18):3383.

25. Perrotta S, Bucci R, Simeon V, Martina S, Michelotti A, Valletta R. Prevalence of malocclusion, oral parafunctions and temporomandibular disorder-pain in Italian schoolchildren: An epidemiological study. J Oral Rehabil. 2019; 46(7): 611-616.

26. Sayin MO, Türkkahraman H. Malocclusion and crowding in an orthodontically referred Turkish population. Angle Orthod. 2004;74(5):635-639.

27. Carvalho ML, Moyses SJ, Bueno RE, Shimakura S, Moyses ST. A geographical population analysis of 
dental trauma in schoolchildren aged 12 and 15 in the city of Curitiba- Brazil. BMC Health Serv Res. 2010; 10: 203-210.

28. Valent F, Brusaferro S, Barbone F. A case-crossover study of sleep and childhood injury. Pediatrics. 2001; 107: 23-29.

29. Serra-Negra JM, Ribeiro MB, Prado IM, Paiva SM, Pordeus IA. Association between possible sleep bruxism and sleep characteristics in children. Cranio. 2017 Sep;35(5):315-320.

30. Ribeiro MB, Manfredini D, Tavares-Silva C, Costa L, Luiz RR, Paiva S, Serra-Negra JM, FonsecaGoncalves A, Maia LC. Association of possible sleep bruxism in children with different chronotype profiles and sleep characteristics. Chronobiol Int. 2018 May;35(5):633-642.

31. Chen H, Tanaka S, Arai K, Yoshida S, Kawakami KJ. Insufficient Sleep and Incidence of Dental Caries in Deciduous Teeth among Children in Japan: A Population-Based Cohort Study. Pediatr. 2018 Jul;198:279-286.e5.

32. Topaloglu-Ak A, Eden E, Frencken JE. Managing dental caries in children in Turkey-a discussion paper. BMC Oral Health. 2009 Nov 25;9:32.

33. Abed R, Bernabe E, Sabbah W.Family Impacts of Severe Dental Caries among Children in the United Kingdom. Int J Environ Res Public Health. 2019 Dec 22;17(1):109.

\begin{tabular}{|c|c|c|c|c|c|c|c|}
\hline & & & Nocturnal Bruxism & Nocturnal Bruxism & Total & $\chi^{2}$ & $\mathrm{p}$ \\
\hline & & & No & Yes & & & \\
\hline \multirow[t]{4}{*}{ TMD } & No & $\mathrm{n}$ & 58 & 33 & 91 & 5,881 & $0,015^{*}$ \\
\hline & & $\%$ & $63,70 \%$ & $36,30 \%$ & $100,00 \%$ & & \\
\hline & Yes & $\mathrm{n}$ & 2 & 7 & 9 & & \\
\hline & & $\%$ & $22,20 \%$ & $77,80 \%$ & $100,00 \%$ & & \\
\hline \multirow[t]{6}{*}{ Angle } & Class I & $\mathrm{n}$ & 47 & 32 & 79 & 2,645 & 0,289 \\
\hline & & $\%$ & $59,50 \%$ & $40,50 \%$ & $100,00 \%$ & & \\
\hline & Class II & $\mathrm{n}$ & 5 & 6 & 11 & & \\
\hline & & $\%$ & $45,50 \%$ & $54,50 \%$ & $100,00 \%$ & & \\
\hline & Class III & $\mathrm{n}$ & 8 & 2 & 10 & & \\
\hline & & $\%$ & $80,00 \%$ & $20,00 \%$ & $100,00 \%$ & & \\
\hline \multirow[t]{4}{*}{ Malocclusion } & No & $\mathrm{n}$ & 26 & 12 & 38 & 1,811 & 0,178 \\
\hline & & $\%$ & $68,40 \%$ & $31,60 \%$ & $100,00 \%$ & & \\
\hline & Yes & $\mathrm{n}$ & 34 & 28 & 62 & & \\
\hline & & $\%$ & $54,80 \%$ & $45,20 \%$ & $100,00 \%$ & & \\
\hline \multirow[t]{4}{*}{ Dental Trauma } & No & $\mathrm{n}$ & 49 & 29 & 78 & 1,175 & 0,278 \\
\hline & & $\%$ & $62,80 \%$ & $37,20 \%$ & $100,00 \%$ & & \\
\hline & Yes & $\mathrm{n}$ & 11 & 11 & 22 & & \\
\hline & & $\%$ & $50,00 \%$ & $50,00 \%$ & $100,00 \%$ & & \\
\hline \multirow[t]{4}{*}{ Dental caries } & No & $\mathrm{n}$ & 2 & 0 & 2 & 1,361 & 0,243 \\
\hline & & $\%$ & $100,00 \%$ & $0,00 \%$ & $100,00 \%$ & & \\
\hline & Yes & $\mathrm{n}$ & 58 & 40 & 98 & & \\
\hline & & $\%$ & $59,20 \%$ & $40,80 \%$ & $100,00 \%$ & & \\
\hline \multirow[t]{2}{*}{ Total } & Total & $\mathrm{n}$ & 60 & 40 & 100 & & \\
\hline & & $\%$ & $60,00 \%$ & $40,00 \%$ & $100,00 \%$ & & \\
\hline
\end{tabular}

${ }^{*} \mathrm{p}<0,05$

Table-1 Association between nocturnal bruxism and TMD, Angle Classification, malocclusion, dental trauma and dental caries

*A significant relation was found among children with nocturnal bruxism and TMD symptoms $\mathrm{p}<0,05$ ). 


\begin{tabular}{|c|c|c|c|c|c|c|}
\hline & & & Nocturnal Bruxism & Nocturnal Bruxism & Total & $\mathrm{p}$ \\
\hline \multirow{3}{*}{ Bed Time Resistance } & \multirow{3}{*}{ No } & & Presence & Absence & & \multirow{3}{*}{$0,020^{*}$} \\
\hline & & $\mathrm{n}$ & 45 & 21 & 66 & \\
\hline & & $\%$ & $68,20 \%$ & $31,80 \%$ & $100,00 \%$ & \\
\hline \multirow{5}{*}{ Sleep Behavior Problem } & Yes & $\mathrm{n}$ & 15 & 19 & 34 & \multirow{4}{*}{0,080} \\
\hline & & $\%$ & $44,10 \%$ & $55,90 \%$ & $100,00 \%$ & \\
\hline & No & $\mathrm{n}$ & 60 & 38 & 98 & \\
\hline & & $\%$ & $61,20 \%$ & $38,80 \%$ & $100,00 \%$ & \\
\hline & Yes & $\mathrm{n}$ & 0 & 2 & 2 & \multirow{4}{*}{0,811} \\
\hline \multirow{3}{*}{ Waking up at night-Sleep fragmentation } & & $\%$ & $0,00 \%$ & $100,00 \%$ & $100,00 \%$ & \\
\hline & No & $\mathrm{n}$ & 58 & 39 & 97 & \\
\hline & & $\%$ & $59,80 \%$ & $40,20 \%$ & $100,00 \%$ & \\
\hline \multirow{5}{*}{ Unable to wake up/Daytime Sleepiness } & Yes & $\mathrm{n}$ & 2 & 1 & 3 & \multirow{8}{*}{0,086} \\
\hline & & $\%$ & $66,70 \%$ & $33,30 \%$ & $100,00 \%$ & \\
\hline & No & $\mathrm{n}$ & 54 & 31 & 85 & \\
\hline & & $\%$ & $63,50 \%$ & $36,50 \%$ & $100,00 \%$ & \\
\hline & Yes & $\mathrm{n}$ & 6 & 9 & 15 & \\
\hline \multirow{3}{*}{ Total } & & $\%$ & $40,00 \%$ & $60,00 \%$ & $100,00 \%$ & \\
\hline & Total & $\mathrm{n}$ & 60 & 40 & 100 & \\
\hline & & $\%$ & $60,00 \%$ & $40,00 \%$ & $100,00 \%$ & \\
\hline
\end{tabular}

Table-2 Association between sleeping habits and nocturnal bruxism

* A significant relation was found among children with nocturnal bruxism and bed time resistance $\mathrm{p}<0,05$

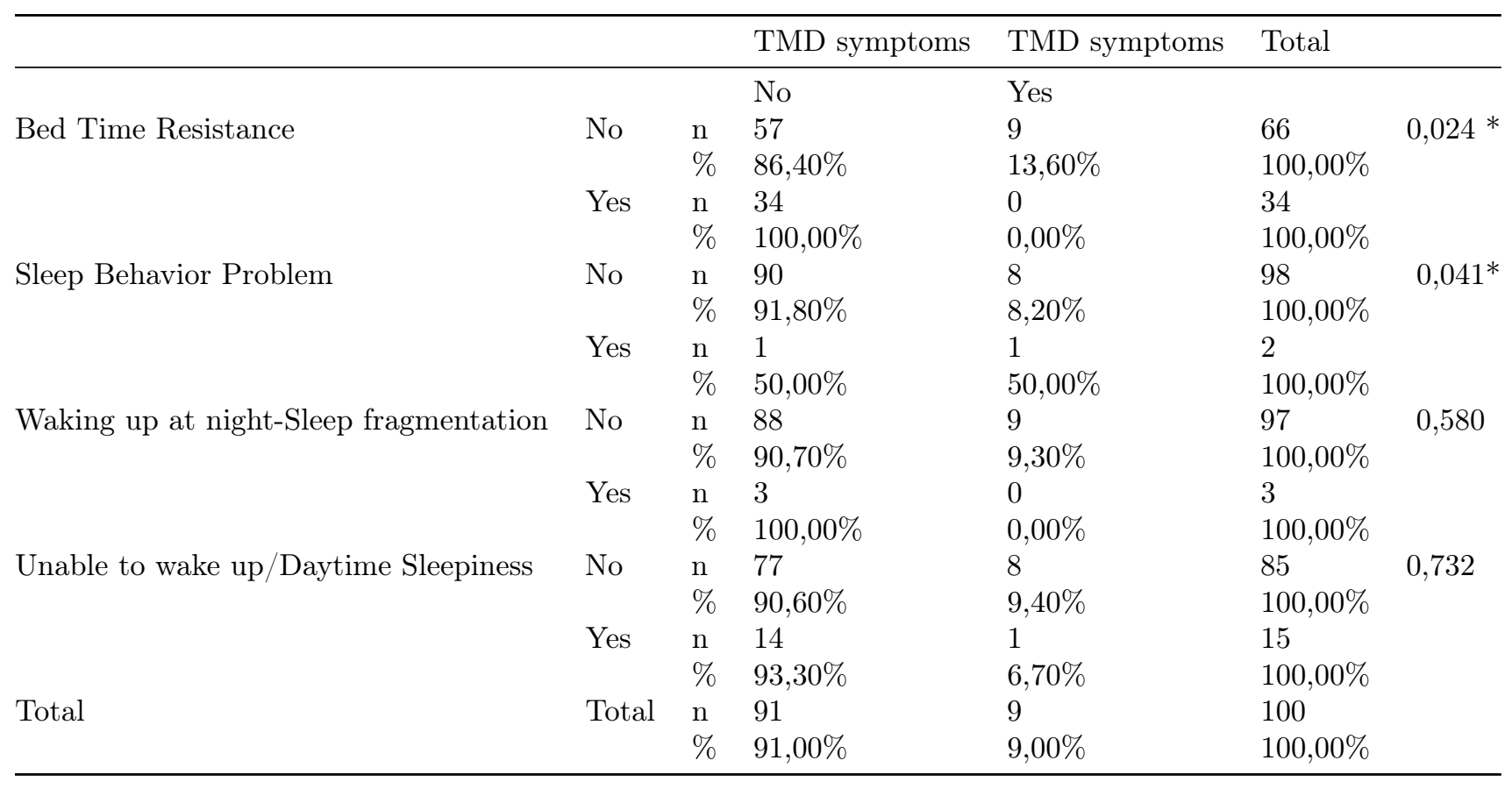

Table-3 Association between sleeping habits and TMD symptoms

* A significant relation was found among children with TMD symptoms and bed time resistance and sleep behaviour $\mathrm{p}<0,05$ 


\begin{tabular}{|c|c|c|c|c|c|c|}
\hline & & & Dental Caries & Dental Caries & Total & $\mathrm{p}$ \\
\hline \multirow{3}{*}{ Bed Time Resistance } & \multirow{3}{*}{ No } & & No & Yes & & \multirow{3}{*}{0,629} \\
\hline & & $\mathrm{n}$ & 1 & 65 & 66 & \\
\hline & & $\%$ & $1,50 \%$ & $98,50 \%$ & $100,00 \%$ & \\
\hline \multirow{5}{*}{ Sleep Behavior Problem } & Yes & $\mathrm{n}$ & 1 & 33 & 34 & \multirow{5}{*}{0,838} \\
\hline & & $\%$ & $2,90 \%$ & $97,10 \%$ & $100,00 \%$ & \\
\hline & No & $\mathrm{n}$ & 2 & 96 & 98 & \\
\hline & & $\%$ & $2,00 \%$ & $98,00 \%$ & $100,00 \%$ & \\
\hline & Yes & $\mathrm{n}$ & 0 & 2 & 2 & \\
\hline \multirow{3}{*}{ Waking up at night-Sleep fragmentation } & & $\%$ & $0,00 \%$ & $100,00 \%$ & $100,00 \%$ & \multirow{3}{*}{$0,001^{* *}$} \\
\hline & No & $\mathrm{n}$ & 1 & 96 & 97 & \\
\hline & & $\%$ & $1,00 \%$ & $99,00 \%$ & $100,00 \%$ & \\
\hline \multirow{5}{*}{ Unable to wake up/Daytime Sleepiness } & Yes & $\mathrm{n}$ & 1 & 2 & 3 & \multirow{8}{*}{0,548} \\
\hline & & $\%$ & $33,30 \%$ & $66,70 \%$ & $100,00 \%$ & \\
\hline & No & $\mathrm{n}$ & 2 & 83 & 85 & \\
\hline & & $\%$ & $2,40 \%$ & $97,60 \%$ & $100,00 \%$ & \\
\hline & Yes & $\mathrm{n}$ & 0 & 15 & 15 & \\
\hline \multirow{3}{*}{ Total } & & $\%$ & $0,00 \%$ & $100,00 \%$ & $100,00 \%$ & \\
\hline & Total & $\mathrm{n}$ & 2 & 98 & 100 & \\
\hline & & $\%$ & $2,00 \%$ & $98,00 \%$ & $100,00 \%$ & \\
\hline
\end{tabular}

Table-4 Association between sleeping habits and dental caries

* A significant relation was found among children with dental caries and bed time resistance $\mathrm{p}<0,05$

\section{Hosted file}

table-1.pdf available at https://authorea.com/users/393881/articles/507377-is-there-arelation-between-sleeping-habits-and-nocturnal-bruxism-temporomandibular-disordersdental-trauma-and-caries-among-children

\section{Hosted file}

table-2.pdf available at https://authorea.com/users/393881/articles/507377-is-there-arelation-between-sleeping-habits-and-nocturnal-bruxism-temporomandibular-disordersdental-trauma-and-caries-among-children

\section{Hosted file}

table-3.pdf available at https://authorea.com/users/393881/articles/507377-is-there-arelation-between-sleeping-habits-and-nocturnal-bruxism-temporomandibular-disordersdental-trauma-and-caries-among-children

\section{Hosted file}

table-4.pdf available at https://authorea.com/users/393881/articles/507377-is-there-arelation-between-sleeping-habits-and-nocturnal-bruxism-temporomandibular-disordersdental-trauma-and-caries-among-children 